\title{
Pengaruh Budaya Organisasi Sekolah dan Efikasi Diri Guru terhadap Etos Kerja Guru
}

\author{
Diyah Rieka Rahmawati*, Ahmad Yusuf Sobri \\ Universitas Negeri Malang, Jl. Semarang No. 5 Malang, Jawa Timur, Indonesia \\ *Penulis korespondensi, Surel: riekarahmaw@gmail.com
}

Paper received: 7-6-2021; revised: 21-6-2021; accepted: 28-6-2021

\begin{abstract}
The purpose of this study was to: (1) describe the school's organizational culture, teacher's selfefficacy, and work ethic for public high school teachers in Pasuruan City; (2) describe the influence of school organizational culture, self-efficacy on work ethics both partially and simultaneously; (3) knowing the differences in characteristics between high school and vocational school. The research method used is a quantitative approach with descriptive data analysis and multiple linear regression. The results of the study showed: school organizational culture, teacher self-efficacy, and work ethic of state senior high school teachers in Pasuruan in a fairly good category; there are significant effects both partially and simultaneously each with a significance value of 0.000 less than 0.05 ; there are differences in characteristics between high school and vocational school with the acquisition of $\mathrm{F}_{\text {count }}$ is 10.4 greater than $\mathrm{F}_{\text {table }}$ is 1.39 at the 0.05 significance level.
\end{abstract}

Keywords: school organizational culture; self efficacy; work ethic

\begin{abstract}
Abstrak
Tujuan penelitian ini untuk: (1) mendeskripsikan budaya organisasi sekolah, efikasi diri guru, dan etos kerja guru SLTA Negeri di Kota Pasuruan; (2) mendeskripsikan pengaruh budaya organisasi sekolah, efikasi diri terhadap etos kerja baik secara parsial maupun simultan; (3) mengetahui adanya perbedaan karakteristik antara SMA dengan SMK. Metode penelitian yang digunakan yaitu melalui pendekatan kuantitatif dengan analisis data deskriptif dan regresi linier berganda. Hasil penelitian menunjukkan: budaya organisasi sekolah, efikasi diri guru, dan etos kerja guru SLTA Negeri di Kota Pasuruan dalam kategori cukup baik; terdapat pengaruh yang signifikan budaya organisasi sekolah, efikasi diri guru, dan etos kerja baik secara parsial maupun simultan masing-masing dengan nilai signifikansi 0,000 kurang dari 0,05; adanya perbedaan karakteristik antara SMA dengan SMK dengan perolehan nilai $F_{\text {hitung }}$ sama dengan 10,4 lebih dari $F_{\text {tabel }}$ sama dengan 1,39 pada taraf signifikansi 0,05.
\end{abstract}

Kata kunci: budaya organisasi; efikasi diri; etos kerja

\section{Pendahuluan}

Peran guru tidak dapat digantikan meskipun hampir seluruh aspek kehidupan termasuk pendidikan bertumpu pada teknologi. Era kemajuan teknologi menandakan bahwa menjadi seorang guru memiliki tugas yang tidak mudah. Seorang guru harus meningkatkan kualitas intelektualnya dan memiliki sikap serta pandangan terhadap kerja yang tinggi. Sikap dan pandangan terhadap kerja merupakan etos kerja guru sebagai wujud profesionalitas dalam melaksanakan pekerjaannya. Bekerja dimaknai sebagai suatu proses yang membutuhkan ketekunan dan berarti bagi mereka yang memiliki etos kerja tinggi. Berbeda bagi mereka dengan etos kerja rendah, bekerja dianggap sebagai sebuah beban. Etos kerja pada diri seseorang tidak tumbuh begitu saja, melainkan perlu mendapat dorongan dari dalam diri sendiri. Keyakinan atas kemampuan diri sendiri (efikasi diri) merupakan salah satu faktor yang dapat memicu seseorang untuk selalu melaksanakan pekerjaan dengan baik. Orang-orang dengan efikasi diri yang tinggi memandang tugas yang sulit sebagai sebuah tantangan dan 
cenderung mendekati tugas sulit tersebut. Selain dipicu oleh keyakinan atas kemampuan diri sendiri, etos kerja memiliki kaitan yang erat dengan budaya di lingkungan seseorang. Sikap dan perilaku anggota organisasi dipengaruhi dan dibentuk melalui nilai-nilai yang tertanam suatu organisasi. Dipandang dan menjadi perhatian para pemerhati dan pengelola pendidikan, budaya organisasi dianggap sebagai suatu hal mendasar dalam meningkatkan dan mempertahankan mutu sekolah. Dampak dari intervensi budaya organisasi memberikan perubahan pada budaya guru yang selanjutnya terjadi perubahan pada proses belajarmengajar sehingga akan terlihat pada hasil belajar peserta didik.

Hasil penelitian Tsaqifah (2016) menunjukkan budaya organisasi sekolah berpengaruh signifikan terhadap kinerja dan kepuasan kerja guru SMA Negeri Kota Malang. Selanjutnya Khayati \& Sarjana (2015) menunjukkan hasil penelitian bahwa memiliki pengaruh positif terhadap kinerja. Sedangkan Tampubolon \& Hutagaol (2015) menyimpulkan bahwa efikasi diri dan etos kerja dengan kepuasan kerja guru berkorelasi kuat. Penelitian ini mengkomposisikan antara budaya organisasi sekolah sebagai variabel (X1), efikasi diri guru (X2), dan etos kerja guru ( Y). Penelitian ini dilakukan pada dua lembaga pendidikan yaitu SMA dan SMK Negeri di Kota Pasuruan dan guru sebagai subyek penelitian.

Sekolah sebagai sebuah organisasi tidak terlepas dari budaya yang diciptakan. Budaya organisasi memiliki peran untuk menjaga dan memelihara komitmen warga sekolahnya sehingga mekanisme dan fungsi yang telah disepakati bersama dapat merealisasikan tujuan yang ingin dicapai. Sekolah juga merupakan tempat dalam mempersiapkan dan membekali peserta didik, membutuhkan guru dengan efikasi diri yang tinggi sehingga dapat memicu etos kerja guru dalam melaksanakan tugasnya untuk memberikan pengajaran yang berkualitas.

\section{Metode}

Penelitian ini dilakukan melalui pendekatan kuantitatif. Variabel yang dicari pengaruhnya adalah budaya organisasi $\left(\mathrm{X}_{1}\right)$ dan efikasi diri $\left(\mathrm{X}_{2}\right)$ terhadap etos kerja guru $(\mathrm{Y})$ dengan analisis data menggunakan model regresi linier berganda. Sedangkan untuk mengetahui perbedaan karakteristik SMA dengan SMK digunakan analisis komparatif melalui statistik Uji F.

Populasi dalam penelitian ini adalah guru SLTA Negeri se-Kota Pasuruan sebanyak 376 orang. Pengambilan jumlah sampel dalam penelitian ini menggunakan rumus slovin dengan perolehan perhitungan sebanyak 197 orang. Teknik penentuan besarnya sampel di setiap sekolahnya menggunakan proportional random sampling karena pengambilan anggota sampel dilakukan secara acak tanpa memperhatikan strata yang ada dalam populasi. Instrumen yang digunakan dalam penelitian ini adalah angket tertutup dengan menggunakan skala rating yang terdiri dari empat kolom pilihan jawaban.

Sebelum digunakan untuk mengukur variabel dalam penelitian, angket terlebih dahulu di uji validitas dan reliabilitas. Penelitian ini menggunakan analisis data berupa statistik deskriptif dan regresi linier berganda. Analisis deskriptif dengan rumus formula stanfive digunakan untuk mendeskripsikan budaya organisasi $\left(\mathrm{X}_{1}\right)$, efikasi diri $\left(\mathrm{X}_{2}\right)$, dan etos kerja $(\mathrm{Y})$. Selanjutnya dilakukan analisis uji asumsi normalitas, uji linieritas, dan uji homogenitas. Apabila ketiga uji asumsi terpenuhi, data dianalisis melalui regresi linier ganda untuk mengetahui sumbangan relatif dan efektifnya. 


\section{Hasil dan Pembahasan}

\subsection{Hasil}

\subsubsection{Deskripsi Data}

\subsubsection{Budaya Organisasi}

Variabel budaya organisasi sekolah diukur dengan 15 item valid dan hasil analisis data menunjukkan skor: maksimal $=60 ;$ minimum $=35$; mean $=46,16$; dan standar deviasi $=5,051$. Diketahui nilai mean variabel budaya organisasi sekolah sebesar 46,16 yang terletak pada interval 43,63 - 48,68. Sehingga budaya organisasi SLTA Negeri di Kota Pasuruan termasuk dalam kategori cukup baik.

\subsubsection{Efikasi Diri}

Variabel efikasi diri diukur dengan 17 item valid dan hasil analisis data menunjukkan skor: maksimal $=67$; minimum $=39$; mean $=52,31$; dan standar deviasi $=5,988$. Diketahui nilai mean variabel efikasi diri sebesar 52,31 yang terletak pada interval 49,31 - 55,30. Sehingga efikasi diri guru SLTA Negeri di Kota Pasuruan termasuk dalam kategori cukup baik

\subsubsection{Etos Kerja}

Variabel etos kerja diukur dengan 18 item valid dan hasil analisis data menunjukkan skor: maksimal $=69 ;$ minimum $=45 ;$ mean $=59,41$; dan standar deviasi $=5,387$. Diketahui nilai mean variabel etos kerja sebesar 59,41 yang terletak pada interval 56,71-62,10. Sehingga etos kerja guru SLTA Negeri di Kota Pasuruan termasuk dalam kategori cukup baik.

\subsubsection{Uji Persyaratan Analisis Data}

Hasil uji normalitas dengan menggunakan Kolmogorov-Smirnov melalui SPSS 18.00 for Windows diperoleh nilai probabilitas (asymp. sig) variabel budaya organisasi sekolah $\left(\mathrm{X}_{1}\right)=$ 0,482; efikasi diri $\left(\mathrm{X}_{2}\right)=0,452$; etos kerja $(\mathrm{Y})=0,107$. Hasil uji signifikansi yang ditunjukkan ketiga variabel $>0,05$ maka dapat dinyatakan data berdistribusi normal.

Hasil uji linieritas dengan menggunakan Test of Linearity melalui SPSS 18.00 for Windows diperoleh nilai Sig. Deviation from linearity sebesar $\left(\mathrm{X}_{1}\right)=0,353>0,05 ;\left(\mathrm{X}_{2}\right)=0,828>0,05$, maka dapat disimpulkan bahwa hubungan variabel penelitian bersifat linier.

Hasil uji homogenitas dengan menggunakan Homogeneity of Variance Test melalui SPSS 18.00 for Windows diperoleh nilai probabilitas (asymp.sig) variabel budaya organisasi sekolah $(X 1)=0,085$; efikasi diri $(X 2)=0,453$; etos kerja $(Y)=0,283$. Hasil uji signifikansi yang ditunjukkan ketiga variabel $>0,05$, maka dapat dinyatakan data berasal dari data yang homogen.

\subsubsection{Pengujian Hipotesis}

Hipotesis pertama yang diajukan adalah terdapat pengaruh yang signifikan antara budaya organisasi sekolah terhadap etos kerja guru SLTA Negeri di Kota Pasuruan. Pengujian menggunakan formula rumus uji t dengan taraf signifikansi 0,05. Nilai signifikansi yang 
diperoleh yakni sebesar 0,000, sehingga dapat diketahui bahwa 0,000 $<0,05$. Dapat disimpulkan bahwa terdapat pengaruh yang signifikan antara budaya organisasi sekolah terhadap etos kerja guru SLTA Negeri di Kota Pasuruan.

Hipotesis kedua yang diajukan adalah terdapat pengaruh yang signifikan antara efikasi diri terhadap etos kerja guru SLTA Negeri di Kota Pasuruan. Pengujian menggunakan formula rumus uji t dengan taraf signifikansi 0,05. Nilai signifikansi yang diperoleh yakni sebesar 0,000, sehingga dapat diketahui bahwa $0,000<0,05$. Dapat disimpulkan bahwa terdapat pengaruh yang signifikan antara efikasi diri terhadap etos kerja guru SLTA Negeri di Kota Pasuruan.

Hipotesis ketiga yang diajukan adalah terdapat pengaruh yang signifikan antara budaya organisasi sekolah dan efikasi diri terhadap etos kerja guru SLTA Negeri di Kota Pasuruan. Pengujian menggunakan formula rumus uji F dengan taraf signifikansi 0,05. Nilai signifikansi yang diperoleh yakni sebesar 0,000, sehingga dapat diketahui bahwa 0,000<0,05. Dapat disimpulkan bahwa terdapat pengaruh yang signifikan antara budaya organisasi sekolah dan efikasi diri secara simultan terhadap etos kerja guru SLTA Negeri di Kota Pasuruan. Berikut hasil Uji F X $X_{1} \mathrm{X}_{2}-\mathrm{Y}$ sebagaimana pada Tabel 1.

Tabel 1. Hasil Uji F $X_{1}-X_{2}-Y$

\begin{tabular}{llccccc}
\hline \multirow{2}{*}{ Model } & \multicolumn{2}{c}{ Unstandardized Coefficients } & Standardized Coefficients & & \\
\cline { 2 - 5 } & & $\mathbf{B}$ & Std. Error & Beta & t & Sig. \\
\hline 1 & (Constant) & 52,238 &, 480 & & 108,895 &, 000 \\
& X1 &, 397 &, 036 &, 539 & 11,040 &, 000 \\
& X2 &, 270 &, 034 &, 393 & 8,040 &, 000 \\
\hline
\end{tabular}

\subsubsection{Uji Persamaan Regresi}

Uji persamaan regresi dalam penelitian ini mengacu pada analisis regresi ganda dua prediktor. Hasil uji linier berganda dalam penelitian ini sebagai berikut:

$\hat{Y}=52,238+0,397 X 1+0,270 X 2$

Interpretasi dari model persamaan regresi tersebut adalah: (1) Nilai konstanta sebesar 52,238 . Berarti jika variabel budaya organisasi sekolah $\left(\mathrm{X}_{1}\right)$ dan efikasi diri $\left(\mathrm{X}_{2}\right)$ tidak ada, maka variabel etos kerja ( $Y$ ) sebesar 52,238; (2) Koefisien regresi $\mathrm{X}_{1}$ sebesar 0,397. Artinya jika nilai variabel budaya organisasi meningkat satu satuan, sedangkan variabel prediktor lainnya tetap, maka tingkat variabel etos kerja guru (Y) akan meningkat sebesar 0,397 satuan. Koefisien regresi bernilai positif, sehingga dapat dikatakan bahwa arah pengaruh variabel $\mathrm{X}_{1}$ terhadap $\mathrm{Y}$ adalah positif; (3) Koefisien regresi $\mathrm{X}_{2}$ sebesar 0,270. Artinya jika nilai variabel efikasi diri $\left(\mathrm{X}_{2}\right)$ meningkat satu satuan, maka tingkat variabel etos kerja guru (Y) akan meningkat sebesar 0,270 satuan. Koefisien regresi bernilai positif, sehingga dapat dikatakan bahwa arah pengaruh variabel $\mathrm{X}_{2}$ terhadap $\mathrm{Y}$ adalah positif. 


\subsubsection{Sumbangan Relatif dan Efektif Variabel Budaya Organisasi Sekolah $\left(X_{1}\right)$ dan Efikasi Diri $\left(\mathrm{X}_{2}\right)$ terhadap Etos Kerja Guru (Y)}

Perhitungan sumbangan relatif dan efektif dalam penelitian ini mengacu pada hasil analisis regresi linier ganda. Hasil perhitungan sumbagan relatif dan efektif sebagaimana pada Tabel 2.

Tabel 2. Sumbangan Relatif dan Efektif $\mathrm{X}_{1}$ dan $\mathrm{X}_{2}$ terhadap $\mathrm{Y}$

\begin{tabular}{lllcc}
\hline Variabel & Beta & $\mathbf{r}_{\mathbf{y x i}}$ & Sumbangan relatif (B . ryxi) & Pengaruh Simultan \\
\hline X1 & 0,539 & 0,724 & 0,390 & \\
X2 & 0,393 & 0,647 & 0,254 & 0,645 \\
X1 dan X2 & & & & \\
\hline
\end{tabular}

Berdasarkan hasil perhitungan pada Tabel 2, maka dapat diketahui sumbangan relatif variabel budaya organisasi sekolah $\left(\mathrm{X}_{1}\right)$ sebesar $39 \%$ dan variabel efikasi diri $\left(\mathrm{X}_{2}\right)$ sebesar $25,4 \%$. Sedangkan untuk sumbangan efektif variabel $X_{1}$ dan $X_{2}$ secara simultan terhadap variabel Y sebesar $64,5 \%$ dan sisanya dengan 35,5\% merupakan kontribusi dari variabel lain di luar variabel-variabel penelitian ini. Adapun perhitungan tersebut diperoleh dari rumus berikut (Gunawan, 2018)

$$
\begin{aligned}
X n & =(\varepsilon 2) 2 \cdot 100 \% \\
& \left.=\sqrt{1-R^{2}}\right) 2 \cdot 100 \% \\
& =(\sqrt{1-0,645)} 2 \cdot 100 \% \\
& =0,355 \cdot 100 \% \\
& =35,5 \%
\end{aligned}
$$

\subsubsection{Analisis Komparatif}

Analisis varians (analysis of variance) tergolong analisis komparatif, baik dari rata-rata dua populasi ataupun lebih dari dua populasi. Distribusi $F$ digunakan untuk menentukan apakah satu populasi lebih bervariasi dibanding populasi yang lain (Gunawan, 2017). Sesusai dengan tujuan analisis untuk mengetahui apakah benar SMA dan SMK memiliki karakteristik yang sama bentuk hipotesisnya adalah:

Ho: $\quad=\sigma^{2} \mathrm{pr} \leq \sigma^{2} \mathrm{lk}$

Ha: $\quad=\sigma^{2} \mathrm{pr} \geq \sigma^{2} \mathrm{lk}$

Statistik uji yang bersesuaian adalah $\mathbf{F}=\mathbf{S}^{2}{ }_{\mathbf{p r}} / \mathbf{S}^{2}{ }_{\text {lk. }}$ Sebelum menghitung nilai $F$, perlu diketahui terlebih dahulu nilai deviasi standar sampel. Deviasi standar dapat dihitung dengan rumus:

$$
\frac{\sqrt{\sum X^{2}-\frac{(X) 2}{n}}}{n-1}
$$


Sehingga diperoleh $\mathrm{F}=17,7 / 1,7=10,4$. Selanjutnya melakukan uji signifikansi dengan memeriksa tabel nilai $\mathrm{F}$ dengan menggunakan dk pembilang $=105 \mathrm{dan} \mathrm{dk}$ penyebut $=89$, diperoleh harga $\mathrm{F}$ teoritik sebesar 1,39 pada taraf signifikansi 5\%. Oleh karena harga $\mathrm{F}$ hitung lebih dari $\mathrm{F}$ tabel, maka Ho ditolak, atau dapat disimpulkan bahwa data memberikan indikasi adanya perbedaan karakteristik antara SMA dengan SMK.

\subsection{Pembahasan}

\subsubsection{Pengaruh Budaya Organisasi Sekolah terhadap Etos Kerja Guru}

Hasil uji hipotesis penelitian ini menunjukkan bahwa terdapat pengaruh yang signifikan budaya organisasi sekolah terhadap etos kerja guru SLTA Negeri di Kota Pasuruan. Hasil penelitian ini selaras dengan hasil penelitian yang dilakukan Nurhakim (2017) menunjukkan bahwa budaya organisasi berpengaruh secara signifikan terhadap etos kerja. Nilai koefisien yang positif yang diperoleh diinterpretasikan dengan semakin baiknya internalisasi budaya organisasi yang dianut oleh karyawan maka etos kerja karyawan pun akan semakin baik. Ki Hajar Dewantara mengajarkan etos kerja dengan sikap dan perilaku kerja mereka yang khas, itulah yang akan menjadi etos kerja dan budaya. Hal tersebut terjadi karena seseorang dan suatu organisasi menganut pada suatu paradigma kerja, mempercayai dan berkomitmen pada paradigma kerja yang telah ditetapkan (Triningsih \& Mundilarno, 2018).

Budaya organisasi di lembaga pendidikan bergantung pada keterlibatan guru dan siswa yang berkelanjutan sehingga tidak hanya sekadar mewujudkan keterampilan pribadi dan profesional dengan pengembangan karir, tetapi juga menyelaraskan hubungan antar sekolah, hubungan intragroup untuk meningkatkan iklim psikologis (Vasyakin, Bogdan, dkk 2016). Oleh karena itu, penentu penting untuk kesesuaian karyawan dengan organisasi adalah budaya organisasi yang disepakati bersama. Kecocokan yang baik antara karyawan dengan organisasi sangat penting karena perbedaan persepsi antar karyawan dapat menyebabkan penurunan etos kerja karyawan (Bingöl, Sener, dkk, 2013).

\subsubsection{Pengaruh Efikasi Diri Guru terhadap Etos Kerja Guru}

Hasil uji hipotesis penelitian ini menunjukkan terdapat pengaruh yang signifikan antara efikasi diri terhadap etos kerja guru SLTA Negeri di Kota Pasuruan. Hasil penelitian yang diperoleh selaras dengan penelitian Arifin, Rahman, dkk (2015) yang menyimpulkan bahwa efikasi diri memberikan pengaruh terhadap etos kerja dan kegigihan seseorang, pengaruhpengaruh yang ditunjukkan terlihat melalui sejumlah perubahan sikap, perilaku, keadaan kognisi dan tindakan seseorang dalam menghadapi masalah. Didukung pula dengan hasil penelitian Rahmayanti dan Kumala (2019) yang menyimpulkan bahwa self efficacy sangat mempengaruhi berbagai aktivitas kehidupan. Perilaku bekerja dibentuk oleh pengaruh lingkungan serta faktor-faktor pribadi seperti efikasi diri dan regulasi diri (Bandura, 2005). Dari pernyataan tersebut, dapat diketahui bahwa etos kerja seseorang tinggi apabila ia memiliki keyakinan fundamental yakni tentang kemampuan dirinya. Self efficacy mengacu pada keyakinan tentang kemampuan seseorang dalam mengorganisasikan dan melaksanakan tindakan untuk pencapaian hasil (Bandura, 1997). Self efficacy mempengaruhi pilihan orang dalam membuat dan menjalankan tindakan yang mereka kejar serta membantu menentukan sejauh mana usaha yang akan dikerahkan seseorang dalam suatu aktivitas (Bandura, 1997). Dengan demikian perilaku seseorang dapat diprediksi melalui self efficacynya meskipun pada 
kenyataannya perilaku itu terkadang berbeda dari kemampuan aktualnya. Jadi, efikasi diri yang tinggi pada seseorang dapat memicu bagaimana sikap seseorang tersebut dalam bekerja, karena efikasi diri menentukan bagaimana orang merasakan, berpikir, memotivasi diri sendiri, dan berperilaku (Bandura, 1997).

\subsubsection{Pengaruh Budaya Organisasi Sekolah dan Efikasi Diri Guru terhadap Etos Kerja Guru}

Berdasarkan hasil uji hipotesis penelitian ini menyimpulkan bahwa terdapat pengaruh yang signifikan antara budaya organisasi sekolah dan efikasi diri terhadap etos kerja guru SLTA Negeri di Kota Pasuruan. Salah satu faktor yang dapat mempengaruhi etos kerja dari seseorang adalah budaya, nilai-nilai budaya yang dimiliki satu komunitas masyarakat akan membentuk kepribadian yang diwujudkan berupa sikap dan perilaku seseorang. Faktor budaya sangat mempengaruhi etos kerja seseorang (Novliadi dalam Pongoh, 2013). Hal ini diperkuat oleh temuan Daoruwan (2009) menyatakan bahwa budaya organisasi adalah faktor utama yang membantu anggota organisasi untuk memahami pekerjaan mereka dan memilih pendekatan yang tepat untuk menyelesaikan masalah. Therefore, organizational culture complements the rational managerial tools by playing an indirect role in shaping and influencing behavior. Budaya organisasi melengkapi alat manajerial dengan memainkan peran tidak langsung dalam membentuk dan mempengaruhi perilaku (Coman \& Bonciu, 2016). Self efficacy mempengaruhi pilihan orang dalam membuat dan menjalankan tindakan yang mereka kejar serta membantu menentukan sejauh mana usaha yang akan dikerahkan seseorang dalam suatu aktivitas (Bandura, 1997). Hasil penelitian Beason (2001) menyatakan bahwa dengan etos kerja setiap individu profesional tidak akan menyerahkan hasil karya yang berkualitas rendah, pekerja profesional akan melakukan segala hal yang mungkin dilakukannya untuk menjunjung tinggi harga dirinya. Seseorang yang merasa bahwa suatu pekerjaan yang diberikan di luar kemampuannya, maka ia akan menolak melakukan pekerjaan itu, dengan demikian internalisasi efikasi diri yang tinggi pada diri seseorang akan menghasilkan etos kerja yang baik pula.

Hal tersebut dapat diinterpretasikan pada delapan paradigma kerja yang melengkapi formulasi etos kerja keguruan dari seorang guru (Sinamo, 2016), yakni: (1) seorang guru yang percaya bahwa hidup keguruannya adalah sebentuk rahmat ia akan mengabdikan dirinya dengan penuh ketulusan dan keikhlasan untuk menjadi pembuluh ilmu, teladan moral, dan pembina keterampilan. Ia akan bersungguh-sungguh menjadi figur panutan bagi masyarakat, sekolah dan khususnya bagi semua siswanya; (2) sebagai pemegang amanah, seorang guru akan sangat mempercayai kompetensi dan integritas yang dimiliki; (3) seorang guru yang meyakini kerja adalah sebuah panggilan, membuat seorang guru mampu memberdayakan diri untuk bekerja dengan motivasi penuh. Ia akan secara religius menghayati perannya sebagai pelaksana tugas suci dan misi luhur; (4) seorang guru yang meyakini kerja adalah arena aktualisasi diri akan bekerja keras dan mendayagunakan seluruh kemampuan biologis, psikologis, dan spiritual yang ia miliki dengan sendirinya akan menjadi sehat lahir batin. Apabila profesi guru diyakini sebagai wahana hidup yang menyehatkan, dalam melaksanakan pekerjaan pun dengan perasaan positif; (5) kemampuan untuk menyadari dan meyakini bahwa aktivitas mengajar bukanlah sekedar kegiatan mencari upah, melainkan juga bentuk ibadah yang memiliki dimensi keagungan dan keluhuran, memiliki konsekuensi yang amat besar. Kesadaran ini mempengaruhi motivasi, perasaan, sikap, kualitas kerja, bahkan kepribadian dan karakter sang guru; (6) profesi guru pun, bila diyakini dan dihayati sampai ke tingkat seni 
pasti mendatangkan kegairahan. Hal ini bersumber dari berbagai aktivitas mengajar yang interaktif, kreatif, dan artistik yang sejatinya akan menggembirakan hati; (7) secara fundamental, kehormatan berakar pada kualitas unggul. Seorang guru yang meyakini bahwa profesi guru adalah kehormatan akan menampilkan cara kerja dan kinerja mengajar yang unggul; (8) meyakini dan menghayati keguruan sebagai pelayanan memerlukan transendensi. Artinya, keguruan harus diterapkan melampaui makna sederhananya. Secara teknis, guru harus bisa mengajar melampaui harapan para pemangku kepentingan. Jadi, bila guru tersebut sedang menjalani dan meyakini profesinya secara profesional, berarti guru tersebut sedang melayani masyarakat dan bangsanya. Itulah sebabnya pekerjaan guru adalah pekerjaan yang mulia.

\subsubsection{Analisis Komparatif SMA dan SMK}

Hasil analisis dengan uji F menunjukkan bahwa adanya perbedaan karakteristik antara SMA dengan SMK. Sekolah Menengah Kejuruan (SMK) memiliki suatu keistimewaan yang tidak dimiliki oleh Sekolah Menengah Umum (SMU). Sekolah Menengah Kejuruan memiliki karakteristik yang membedakan dengan sekolah lainnya. SMK memiliki tujuan institusional yang lebih menekankan pada penguasaan kemampuan yang bersifat praktis agar peserta didik yang dipersiapkan mampu dan siap pakai di dunia industri. Kurikulum yang digunakan menitik beratkan pada penguasaan keterampilan sehingga strategi pembelajarannya lebih ditekankan pada praktik daripada teori. Sekolah Menengah Kejuruan menyelenggarakan pendidikan dan pelatihan berbagai program studi keahlian sesuai dengan kebutuhan lapangan kerja (Ramadhina, 2015). Sedangkan orientasi Sekolah Menengah Atas lebih pada mempersiapkan untuk bersaing di perguruan tinggi tanpa bekal sebuah keahlian khusus.

\section{Simpulan}

Budaya organisasi SLTA Negeri di Kota Pasuruan termasuk dalam kategori cukup baik dengan nilai mean sebesar 46,16; efikasi diri guru SLTA Negeri di Kota Pasuruan termasuk dalam kategori cukup baik dengan nilai mean sebesar 52,31; etos kerja guru SLTA Negeri di Kota Pasuruan termasuk dalam kategori cukup baik dengan nilai mean sebesar 59,41; terdapat pengaruh yang signifikan budaya organisasi terhadap etos kerja guru SLTA Negeri di Kota Pasuruan dengan nilai signifikansi yang diperoleh $0,000<0,05$; terdapat pengaruh yang signifikan efikasi diri terhadap etos kerja guru SLTA Negeri di Kota Pasuruan dengan nilai signifikansi yang diperoleh yakni sebesar $0,000<0,05$; terdapat pengaruh yang signifikan budaya organisasi dan efikasi diri terhadap etos kerja guru SLTA Negeri di Kota Pasuruan dengan nilai signifikansi yang diperoleh yakni sebesar $0,000<0,05$; adanya perbedaan karakteristik antara SMA dengan SMK dengan perolehan nilai $F_{\text {hitung }}=10,4>F_{\text {tabel }}=1,39$ pada taraf signifikansi 0,05, sehingga Ho ditolak.

\section{Daftar Rujukan}

Arifin, S., \& Asdar, A. R. (2015). Profil pemecahan masalah matematika siswa ditinjau dari gaya kognitif dan efikasi diri pada siswa kelas VIII unggulan SMPN 1 Watampone. Daya Matematis: Jurnal Inovasi Pendidikan Matematika, 3(1), 20-29.

Bandura, A. (1997). Self Efficacy: The Exercise of Control. New York: W.H. Freeman.

Beason, L. (2001). Ethos and Error: How Business People React to Errors. The National Council of Teachers of English. (http://faculty.winthrop.edu/kosterj/writ465/samples/beason.pdf).

Bingöl, D., Şener, İ., \& Çevik, E. (2013). The effect of organizational culture on organizational image and identity: Evidence from a pharmaceutical company. Procedia-Social and Behavioral Sciences, 99, 222-229. 
Coman, A. \& Bonciu, C. (2016). Organizational Culture in Higher Education: Learning From The Best. European Journal of Social Sciences Education and Research, 3(1), 135-145.

Daoruwan, T. (2009). Organizational Culture of The Loyal Academy: Ethnography Research. Khon Kaen: The Faculty of Education of Khon Kaen University.

Gunawan, I., Kusumaningrum, D. E., Triwiyanto, T., Zulkarnain, W., \& Nurabadi, A. (2018). Laporan Penelitian PNBP Jurusan: Pengaruh Kurikulum Tersembunyi dan Pembentukan Karakter Terhadap Motivasi Diri Mahasiswa Ormawa Fakultas Ilmu Pendidikan Universitas Negeri Malang. Malang: Universitas Negeri Malang.

Gunawan, I. (2017). Pengantar Statistika Inferensial. Jakarta: Rajawali Pers

Khayati, N., \& Sarjana, S. (2015). Efikasi diri dan kreativitas menciptakan inovasi guru. Jurnal Pendidikan dan Kebudayaan, 21(3), 243-262.

Nurhakim, L. (2017). Pengaruh Budaya Organisasi Terhadap Kinerja Karyawan Lulusan Akademi Komunitas Toyota Indonesia. Skripsi tidak diterbitkan. Bogor: Program Sarjana Alih Jenis Manajemen Departemen Institut Pertanian Bogor. (https://repository.ipb.ac.id/handle/123456789/89547).

Pongoh, S. (2013). Etos Kerja Guru (Faktor yang Memengaruhi dan Dipengaruhi). Surabaya: CV. R.A De Rozarie.

Rahmayanti, N. (2019). Hubungan Self Efficacy dengan Toleransi Keberagaman Antar Etnis. Prosiding Konferensi Nasional Peneliti Muda Psikologi Indonesia, 4(1), 101-112.

Ramadhina, S. (2015). Pembuatan Sistem Informasi Manajemen Bengkel di Sekolah Menengah Kejuruan Negeri 3 Yogyakarta. Jurnal Pendidikan Teknologi dan Kejuruan, 22(3), 324-338.

Sinamo, J. (2016). 8 Etos Kerja Keguruan. Jakarta: Erlangga.

Tampubolon, R., \& Hutagaol, S. (2015). Hubungan Antara Efikasi Diri dan Etos Kerja dengan Kepuasan Kerja Guru SMAK Penabur Harapan Indah Kota Bekasi. Jurnal Manajemen Pendidikan, 4(2), 187-204.

Trinigsih, E. \& Mundilarno. (2018). Produktivitas Kerja Guru Ditinjau dari Kontribusi Etos Kerja, Kepemimpinan Transformasional, Komitmen Organisasi di SMA/SMK. Media Manajemen Pendidikan, $1(2), 277-286$.

Tsaqifah, Q. A. (2016). Pengaruh Budaya Organisasi Sekolah Terhadap Kinerja dan Kepuasan Kerja Guru di SMA Negeri Kota Malang. Skripsi tidak diterbitkan. Malang: Program Sarjana Jurusan Administrasi Pendidikan Fakultas Ilmu Pendidikan Universitas Negeri Malang.

Vasyakin, B. S., Ivleva, M. I., Pozharskaya, Y. L., \& Shcherbakova, O. I. (2016). A Study of the Organizational Culture at a Higher Education Institution [Case Study: Plekhanov Russian University of Economics (PRUE)]. International Journal of Environmental and Science Education, 11(10), 11515-11528.

Yuliarti. (2016). Pengaruh Etos Kerja, Disiplin Kerja dan Komitmen Organisasi Terhadap Kinerja Pegawai Pada Dinas Perumahan dan Penataan ruang Daerah Kabupaten morowali. Jurnal Katalogis, 4(8), 101-108. 